\title{
Susumu Ohno: The father of X-inactivation
}

\author{
E. Beutler \\ Department of Molecular and Experimental Medicine, The Scripps Research Institute, La Jolla CA (USA) \\ Dedicated to Dr. Susumu Ohno on the occasion of his 70th birthday.
}

It is not unusual to be told by a friend about the work of a colleague whom one has never met; it is less common when the colleague works at the same, relatively small institution. But this is how I first heard about Susumu Ohno. In the summer of 1960 I was at a meeting in New York with my friend Arno Motulsky, having moved from the University of Chicago to assume the Chairmanship of the Department of Medicine at the City of Hope. "You have a very bright young scientist working with the X-Chromosome at the City of Hope", Arno commented during a coffee break. "Have you met him?" Although I had been there for over half a year, I had not. I could not even remember hearing his name mentioned.

In August of 1960 I participated in a panel at the 4th International Congress of Clinical Chemistry in Edinburgh, Scotland (Beutler, 1960). After my presentation Harry Harris asked me why females, being endowed with two X-chromosomes, did not have more glucose-6-phosphate dehydrogenase (G6PD) activity than did males. Frankly, this problem had not occurred to me, and although at the time I muttered some suggestions of feedback control, the question continued to trouble me. The next month, Sept. 4-10, 1960 I attended the 8th International Congress of the International Society of Hematology. I had still not met my City of Hope colleague, Susumu Ohno, but fortunately he had been invited to give a major talk at the congress, and I made it a point to attend his presentation. He spoke about the X-chromosome and his demonstration that the two X-chromosomes were different morphologically. I didn't understand everything he said, partly because the topic was new to me and perhaps because Ohno's mastery of English was as yet incomplete (perhaps particularly so when speaking English in Tokyo). I met Susumu there for the first time a little strange to meet a colleague from my own institution so far away. That evening I went to dinner with Arno Motulsky and we talked late into the night about science. He helped fill in for me things that I had not understood in Susumu's presentation. The idea that the X-chromosome that was highly condensed might be inactive, thus explaining the conundrum that had been raised the previous month, was a simple extension of what Ohno had demonstrated. It led directly to my formulation (Beutler, 1962a; Beutler et al., 1962b), and that of others (Lyon, 1961; Russell, 1961) of the X-inactivation hypothesis.

While my first introduction to the difference between the two X-chromosomes of female mammals was directly from the lips of Susumu Ohno, his prolific writings make it clear that X-chromosome inactivation had occurred to him as well. His classical studies on germ and somatic cells of the Norwegian rat were morphological in nature (Ohno et al., 1960; 1959; 1961). He wrote:

The distinct cytological and genetic (emphasis added) properties of sex chromosomes in general have been attributed to their heterochromatic nature. This characteristic cytologic behavior was first identified in an insect... .

The effect of heterochromatin on gene function had long been appreciated (see review by S.W. Brown (Brown, 1966) and the step from morphology to function was a short and obvious one.

\footnotetext{
Request reprints from Dr. Ernest Beutler M.D., Department of Molecular and Experimental Medicine, The Scripps Research Institute, 10550 North Torrey Pines Road, La Jolla, CA 92037 (USA);

telephone: (619) 784-8040; fax: (619) 784-2083; email: beutler@scripps.edu
} 
As early as 1959 (Ohno et al., 1959) Ohno also gave consideration to the origin of the putatively inactive $\mathrm{X}$-chromosome. Here he wrote:

It is of extreme interest that the two X-chromosomes of the homogametic sex do not behave identically in liver cells. One exhibits outstanding positive heteropycnosis, and the other appears isopycnotic to the autosomes. At present, the explanation for this can only be conjectured. Perhaps the derivation of the $X$ chromosome determines whether the heteropycnotic condition is manifested during interphase and prophase. The paternally derived $X$-is the one expected to evidence this behavior since the male carries only a maternally derived $X$-chromosome. Further experimental work is necessary in order to explore this possibility.

While this proved to be true in marsupials as well as in extra-embryonic membrane cells of eutherian mammals, to explain X-linked inheritance inactivation had to be random. As a physician, I recognized that if the paternal X-chromosome were always the inactive one, then female heterozygotes for diseases such as glucose-6-phosphate dehydrogenase deficiency, which I had been studying intensely, would never manifest a defect of intermediate severity. Indeed, the marked variation of the phenotype of female heterozygotes was easily explained by random inactivation (Beutler et al., 1962b).

Having fathered the critical concept of inactivation of one X-chromosome in female mammals, Susumu Ohno continued to expand our knowledge of the inactivation phenomenon. Notably, his investigation with Lyon, Searle and Ford (Lyon et al., 1964) showed that X-chromosomal translocations introduced a severe bias of the X-linked phenotype, and suggested that the X-inactivation process may spread, involving adjacent DNA. Referring also to Russell who had independently made a similar formulation, they wrote:

There might be some centre or centres from which the inactivation spread (Lyon, 1964; Russell, 1964). Then any part of the $X$ separated from this centre by translocation would not be inactivated. If a sufficient number of X-linked translocations with breaks at various points could be studied it should be possible to locate such a centre if it existed. At present, however, this evidence is not available. On the other hand there is the point that probably it is the maintenance of activity rather than inactivation that requires some positive process ... This might depend on an activation centre or centres or on some more general property of the chromosome, such as size. Again the evidence is not sufficient to test this point.

This early interpretation fits well with the molecular data that is now being developed (Willard, 1996).

Ohno has been responsible for numerous further insights into the sex chromosomes. In his 1967 book "Sex Chromosomes and Sex-Linked Genes" (Ohno, 1967) Ohno proposed that sex chromosomes were originally a pair of homologous chromosomes and subsequent differentiation to the $\mathrm{X}$ and $\mathrm{Y}$ as we know them occurred exclusively at the expense of the Y. He recognized the conservation in toto of the X-linkage group by eutherian mammals. This concept now widely confirmed, became known as "Ohno's law". It is likely that the $\mathrm{X}$ chromosome was protected from the extensive rearrangements of the autosomes that has led to the wide diversity of chromosome patterns in mammals by the very inactivation process that he was the first to recognize. Pieces of autosomes translocated to the $\mathrm{X}$ chromosome could be inactivated, thereby producing strong selection against such events. Conversely, pieces of the $\mathrm{X}$ chromosome translocated to autosomes might escape inactivation and the loss of dosage compensation of those genes brought about by the loss of $\mathrm{X}$ inactivation would, again, serve as a negative selecting force against such events.

Who knows what our state of understanding of the X-chromosome would be without Susumu Ohno's seminal contributions?

\section{References}

Beutler E: Congenital metabolic abnormalities of the erythrocyte; drug sensitivity and galactosemia. Proc 4th Int Cong Clin Chem, Edinburgh, pp 110118 (1960).

Beutler E: Biochemical abnormalities associated with hemolytic states, in Weinstein IM, Beutler E (eds): Mechanisms of Anemia in Man, pp 195-236 (McGraw-Hill, New York, 1962a).

Beutler E, Yeh M, Fairbanks VF: The normal human female as a mosaic of X-chromosome activity: Studies using the gene for G-6-PD deficiency as a marker. Proc natl Acad Sci, USA 48:9-16 (1962b).
Brown SW: Heterochromatin. Science 151:417-425 (1966).

Lyon MF: Gene action in the X-chromosome of the mouse (Mus musculus L.). Nature 190:372-373 (1961).

Lyon MF, Searle AG, Ford E, Ohno S: A mouse translocation suppressing sex-linked variegation. Cytogenetics 3:306-323 (1964).

Ohno S: Monographs on Endocrinology. Sex Chromosomes and Sex-linked Genes, 1st edition (Heidelberg, Springer-Verlag, 1967).
Ohno S, Kaplan WD, Kinosita R: Formation of the sex chromatin by a single X-chromosome in liver cells of Rattus norvegicus. Exp Cell Res 18:415-418 (1959).

Ohno S, Kaplan WD, Kinosita R: On isopycnotic behavior of the XX-bivalent in oocytes of Rattus norvegicus. Exp Cell Res 19:637-639 (1960).

Ohno S, Kaplan WD, Kinosita R: X-chromosome behavior in germ and somatic cells of Rattus norvegicus. Exp Cell Res 22:535-544 (1961).

Russell LB: Genetics of mammalian sex chromosomes. Science 133:1795-1803(1961).

Willard HF: X chromosome inactivation, XIST, and pursuit of the X-inactivation center. Cell $86: 5-7$ (1996). 